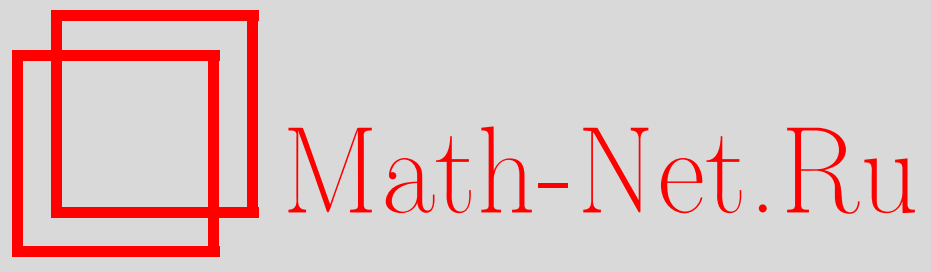

М. Г. Князева, Г. Ю. Панина, О неизотопных седловых ежах, УМH, 2008, том 63, выпуск 5, 189-190

DOI: https://doi.org/10.4213/rm9236

Использование Общероссийского математического портала Math-Net.Ru подразумевает, что вы прочитали и согласны с пользовательским соглашением http://www . mathnet.ru/rus/agreement

Параметры загрузки:

IP: 3.85 .73 .92

26 апреля 2023 г., 16:11:37

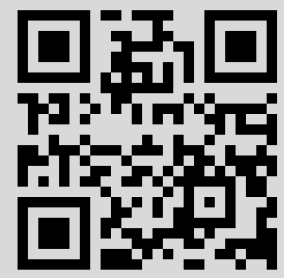




\section{О неизотопных седловых ежах}

\section{М. Г. Князева, Г. Ю. Панина}

В 2001 г. французский математик И. Мартинес-Мор построил следующий интересный объект [1]. Это ориентированная замкнутая поверхность $M$ в $\mathbb{R}^{3}$ (см. рис. 1), обладающая следующими свойствами.

1) Поверхность $M$ гладкая и седловая во всех своих точках (за исключением четырех, называемых рогами).

2) Поверхность $M$ обладает корректно определенной непрерывной опорной функцией. В частности, это свойство означает, что гауссово отображение $M \rightarrow S^{2}$ инъективно.

3) Опорная функция $h_{M}$ поверхности $M$ гладкая, и ее график есть гладкая седловая поверхность.
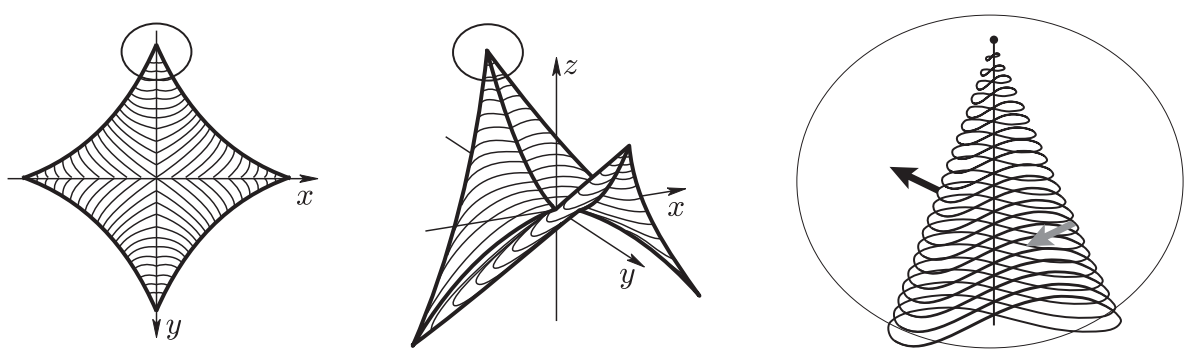

Рис. 1. Поверхность $M$

ОПРеДЕлЕниЕ 1. Замкнутые поверхности, обладающие свойством 2), называются ежами. Замкнутые поверхности, обладающие свойствами 1)-3), называются седловыми (или гиперболическими) ежсами с четыръмя рогами.

Поверхность $M$ интересна сразу с нескольких точек зрения:

1) она представляет собой новый тип седловой поверхности (пропущенный в существовавшей до сих пор классификации);

2) она порождает контрпример к следующей гипотезе А. Д. Александрова (подробнее об этом см. [1]-[4]): пусть $K \subset \mathbb{R}^{3}$ - гладкое выпуклое тело; если для постоянной $C$ в каждой точке границы $\partial K$ выполнено неравенство $R_{1} \leqslant C \leqslant R_{2}$, то тело $K$ - шар $\left(R_{1}\right.$ и $R_{2}$ - главные радиусы кривизны

3) другие приложения см. на сайте [4].

ОПределЕниЕ 2. Будем говорить, что седловые ежи с четырьмя рогами $L$ и $N$ изотопны, если существует непрерывное семейство $N_{t}, t \in[0,1]$, седловых ежей с четырьмя рогами таких, что $N_{0}=L$ и $N_{1}=N$.

Настоящая статья анонсирует следующий результат.

Теорема 3. Существует поверхность $N$, обладающая свойствами 1)-3), не изотопная поверхности $M$. При этом пример поверхности $N$ построен явно.

Построенная поверхность $N$ порождает новый контрпример к гипотезе А. Д. Александрова и представляет новый тип седловой поверхности (по сравнению с уже известными, включая поверхность $M)$. 
Мы располагаем двумя способами ее построения. У каждого из них есть свои преимущества и свои недостатки. В обоих случаях сначала строится дискретный аналог седлового ежа - так называемый гиперболический виртуальный многогранник $N^{\prime}$ (здесь используется техника, разработанная в [6] и развитая далее в [2], [3]).

Благодаря существующей технике сглаживания (см. [3]), гладкая поверхность $N$ получается автоматически.

ПЕрвый сПосоБ Построения (Г. Ю. Панина). Мы строим не саму многогранную поверхность $N^{\prime}$, а двойственный объект - график ее опорной функции $\Gamma$, натягивая его на специальным образом построенное зацепление. При этом остаются неясными внешнегеометрические свойства самой поверхности $N^{\prime}$. Она, разумеется, определяется графиком $\Gamma$, но явные вычисления и визуализация технически трудны.

Второй спосоь (М. Г. Князева). Форма искомой поверхности была угадана, после чего был предъявлен гиперболический виртуальный многогранник (рис. 2). Это поверхность тетраэдра с четырьмя приклеенными дважды покрытыми треугольниками

Неизотопность ежей $M$ и $N$ вытекает из следующей леммы.

Лемма 4. Образ рога всякого гладкого гиперболического ежа при отображсени Гаусса содержит болъшой полукруг (т.е. половину большого круга).

Следовательно, всякий гиперболический еж с четырьмя рогами порождает конфигурацию четырех непересекающихся больших полукругов на единичной сфере.

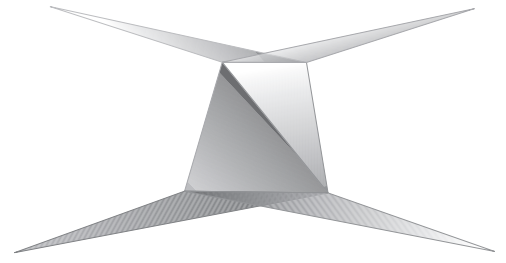

Рис. 2
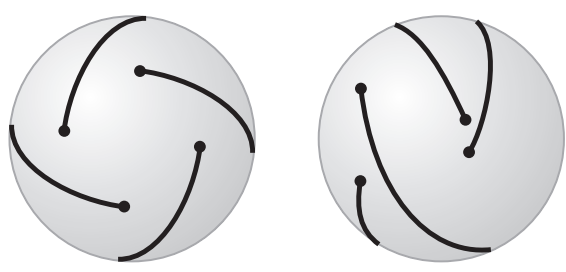

Рис. 3

Однако известно [1], что еж $M$ порождает конфигурацию I (см. рис. 3, слева), тогда как ежи $N$ порождают конфигурацию II (см. рис. 3, справа). Именно эта цель преследовалась при построении $N$. А эти две конфигурации неизотопны, т. е. они не переводятся одна в другую непрерывным движением, избегая самопересечений.

\section{Список литературы}

[1] Y. Martinez-Maure, C.R. Acad. Sci. Paris, Ser. I Math., 332:1 (2001), 41-44. [2] G. Panina, Adv. Geom., 5 (2005), 301-317. [3] G. Panina, Cent. Eur. J. Math., 4:2 (2006), 270-293. [4] http://club.pdmi.ras.ru/ panina/hyperbolicpolytopes.html (сайт, посвященный гиперболическим виртуальным многогранникам). [5] А.Д. Александров, Докл. АН СССР, 22:3 (1939), 99-102. [6] А. Пухликов, А. Хованский, Алгебра и анализ, 4:2 (1992), 161-185; англ. пер.: A. V. Pukhlikov, A. G. Khovanskii, St. Petersburg Math. J., 4:2 (1993), 337-356.

\section{М. Г. Князева (M. G. Knyazeva)}

Санкт-Петербургский институт информатики и автоматизации РАН

E-mail: marinakn@mail.ru
Представлено В. М. Бухштабером Принято редколлегией 01.08 .2008

\section{Г. Ю. Панина (G. Yu. Panina)}

Санкт-Петербургский институт информатики и автоматизации РАН

E-mail: panina@iias.spb.su 